\title{
Building physics into the social: Enhancing the policy impact of energy studies and energy social science research
}

Adam C.G. Cooper

UCL Department of Science, Technology, Engineering and Public Policy

36-38 Fitzroy Square, London W1T 6EY, UK

email:adam.cooper@ucl.ac.uk

\section{Abstract}

A diagnosis for why the social sciences have limited impact on energy policy-making is proposed, and the outline of a remedy presented. The diagnosis identifies the limited use physical science in social studies of energy as a major cause of this lack of impact. This is illustrated by a qualitative review of studies in psychological and sociological approaches and by a quantitative content analysis of all the articles published in Energy Research and Social Science to July 2016 . Only around one in ten papers make any meaningful reference to common physical units for energy analysis, with nearly three-quarters making no reference at all to any of these units, in contrast to the pattern observed in the journal Energy Policy. This is important because while it is possible to make realistic but problematic energy policy with only physical and technical data it is not possible to make realistic energy policy with only social data. To bring more physics into social science of energy without the latter simply serving the framework of the former demands a new socio-technical approach to the study of energy. A potential vision for this approach is set out in order to stimulate wider debate in the academy.

Keywords: interdisciplinarity; energy policy; physical data; socio-technical;

\section{Introduction}

Social scientists from beyond economics (here, the phrase 'broader social science' is used from this point on) have for years made calls for more involvement in energy policy [1-6]. The principle concern has been that energy policy has been dominated by a technical/physical approach which means energy policy-making has missed out and misunderstood the human and social context of energy demand. Commonly this argument is made largely on the basis of broader social science being important for making changes to society, so if they are not involved then we are less able "to achieve a future energy system that enhances human well-being" [1]. While it is hard to argue against this claim as a social scientist, this author suspects it is not persuasive to public policy teams that comprise the main target audience for impact. As the one-time Head of Social Science Engagement at the then UK government Department for Energy and Climate Change (DECC, from 2011 to 2013) the author has direct experience in this area. While policy officials might agree with such claims, they rarely turn to the social sciences for energy policy analysis because such studies regularly fail to provide the sort of answers energy policy demands. At its simplest this relates to the goals of energy policy being implicitly set out in physical science units. For instance, energy security is based on the installed capacity, fuel poverty on costs of energy 


\section{Energy Research and Social Science}

and implicitly, a lack of thermal resistance in building infrastructure, and climate targets defined in terms of weight of greenhouse gas emissions. To answer questions framed in these terms, answers with these terms are needed, or they can have no traction. One might question whether such policy goals are framed in a way that most benefits society. This is an important question which underpins the definition 'most impact' that the social sciences might have. It is addressed here by first recognising that physical units are necessary but not sufficient for effective energy policy: energy is a real, physical substance that needs to be generated, moved, transformed and managed by other physical process and substances. But the point (construction, management and use) of the energy system is entirely social. Consequently, the lack of broader social science approaches in the description and analysis of energy policy reflects an absence of deep impact by the broader social sciences. The remedy suggested here is not simply to do more social science disconnected from the physical context, or to do more 'end of pipe' social science in a physical context [7] but to do more interdisciplinary, integrated socio-technical research that reflects the integrated nature of the physics and the social in these systems.

First, though, the relative success of broader social sciences in energy policy is reviewed, before a diagnosis for the lack of impact that many claim is presented. It is important to note that the analysis presented here is focused principally on the UK experience - though the underpinning arguments (and evidence) go beyond this. As a consequence, one goal of this paper is to prompt wider debate on the impact of social science approaches for energy policy in different jurisdictions.

\section{Where has broader social science been successful in influencing energy policy?}

Only recently has broader social science had any success with calls for integration into energy policy-making circles. In the UK that success is mainly from what has come to be known as 'behavioural science' and in particular behavioural economics. In the UK, this began with the recent (2010-2015) Coalition government's interest in 'Nudges' [8] and then developed into the support for a Behavioural Insights Team (BIT) at the UK Cabinet Office on the back of the then Director's authorship of document called 'MINDSPACE' [9]. The BIT went on to conduct a range of 'behavioural' studies with DECC in order to demonstrate the benefit of this approach [10-12]. At around the same time DECC grew its internal social research capacity (mainly as a 'Customer Insight team') from near zero staff to a partially dispersed group of around 15 (in contrast to the around 90 economists and 40-50 engineers and physical scientists in a total staff headcount of about 800). From there, and with my appointment, the broader social sciences started to take greater prominence with the creation of a 'Social Science Expert Panel' for DECC and sister department Defra (Department for the Environment, Food and Rural Affairs). The panel comprised 13 social science experts across energy and environment and drawn from psychology, sociology, politics and evolutionary economics. In addition, the UK Committee on Climate Change (an independent advisory body to DECC) appointed in 2015 its first ever social scientist, Nick Chater, Professor of Behavioural Science ${ }^{1}$. Finally, in 2014, the UK's Research Councils (led

\footnotetext{
${ }^{1}$ See: https://www.theccc.org.uk/about/structure-and-governance/committee-on-climate-change/ Accessed 27 October 2016
} 


\section{Energy Research and Social Science}

by the Engineering and Physical Sciences Research Council) funded 6 energy demand research centres, one of which is grounded in the sociology of energy demand ${ }^{2}$.

Two points can be made from this success story, such as it is. The first is the focus on 'behavioural science' as the main way of bringing in broader social sciences. This success is a double-edged sword for the social sciences: on the one hand, finally there is some kind of social science involvement in policy making; but on the other, the focus on behavioural science is a strengthening of the standard (techno-economic) approach to energy policy [4, 5]. The focus is clearly on addressing the obvious shortcomings of treating the energy system as a purely technical system, rather than widening horizons to take account of what energy is for and patterns of use and deployment might be reconstituted to meet energy and climate policy goals.

The second (and perhaps more contentious) point is to note that energy policy in the UK has not noticeably improved since 2010. Major policy programmes have been cancelled, amended due to recognised failings or significantly delayed (including the UK Green Deal, the feed in tariff scheme for solar photovoltaics, carbon capture and storage innovation, fracking policy, new nuclear power, on and off shore wind turbine development and so on). For many of these, the failure to take on board broader social science input can be seen as one among a set of causes for these issues. Further, the failure of policies to work in intended ways misses either unintended benefits of supposedly 'failed' energy policy that a broader social science could recast as success (e.g. FITS scheme developing social energy enterprises), or unintended costs that are not detected by the standard policy analysis approach (e.g. communities mobilised against energy developers due in part to planning processes).

\section{The real barrier facing social science for energy policy impact: physics}

Here, my focus is on diagnosing why broader social science has had limited impact on energy policy making. Why it fails to gain any traction despite both longstanding calls for more involvement, several open doors and sympathetic ears from the institutions within which they must operate. The principle hypothesis offered here is that the lack of real consideration of the properties of physical 'stuff' within a significant body of social science studies of energy prevents deeper policy impact. This is, in effect, the mirror image of the problem social scientists diagnose with the technical-led studies of energy - the lack of real consideration of the properties of social 'stuff' [1]. It is worth noting that the choice of the term 'real' in this context is quite deliberate - as the underlying position here is that (critical) realist perspective is needed to bring together epistemic communities from physical sciences with those from broader social sciences [13]. While there is no doubt that social science has provided important insights in this domain around risk analysis, public acceptance and attitudes [e.g. 14-16], the point here is that such input has so far failed to affect day to day policy analysis at the national level in the UK at least. And crucially such input often fails to widen the horizons of policy options, reinforcing the standard framing [6, 7].

\footnotetext{
${ }^{2}$ See: http://www.demand.ac.uk Accessed 27 October 2016
} 


\section{Does social science of energy give no real consideration to physics?}

Perhaps one of the ironies of this whole debate is that the one part of the broader social sciences that has been embraced by energy policy, the so-called 'behavioural sciences' is the one part of the broader social sciences that is often critiqued for taking a 'physics-like' approach to studying the social (i.e. positivist/empiricist), but arguably does the least to acknowledge and promote the idea that physical stuff is an important consideration in shaping social (and therefore policy) outcomes. While the one area that is perhaps most distant from having a direct impact - social theory - is in many respects much better placed to address these issues. This irony is best demonstrated by reference to relevant studies from the different perspectives. But either way, the argument presented here is that the vast majority of mainstream social science of energy research pays little or no real attention to the physical property of stuff, and that lack of attention underpins a lack of policy impact.

\section{Behavioural/psychological approaches to energy research}

It is not possible to do proper justice to the range of approaches from this angle here, but it is probably uncontentious to state that (social and cognitive) psychological approaches in energy research regularly fail to recognise the significance of physics, privileging instead mental states and processes. Some examples can illustrate this. For instance, the document underpinning the BIT studies in the UK - MINDSPACE - focuses on issues of 'messenger' (who is telling you some information), 'incentives' (psychological states induced by proposed rewards), 'norms' (beliefs about what others would typically do), 'defaults' (implied standards in specific settings), 'salience' (how some information stands out), 'priming' (the automatic triggering of mental states), 'affect' (the emotions provoked by some context), 'commitment' (the sense of duty ensuring an action is undertaken) and 'ego' (doing things to appear better). These all make little or no reference to the importance of the physical character of non-human materials.

This approach is also visible in academic energy research. For instance, Never [17] examined Ugandan entrepreneurs' energy use and interprets their approach to managing energy demand through a behavioural economics lens. What matters most are the psychological states (cognitive self-control) and mental processes (immediacy effects in discounting) not the properties of the physical context. This is despite the fact that this context is clearly extremely important to her respondents who regularly refer to "The visible stock, machinery and degree of maintenance" (p. 40), "the habits of their owners, managers or employees in the operation of machinery and equipment-with direct consequences for their electricity bill" ( $p .41)$ and "The introduction of a new electricity metering system by Umeme can be understood as such a change of the triggering environment." (p.42, all emphasis added). In the entire 11-page article there is only one reference to a physical unit of energy (kilowatt hours, kWh). The physical world is of course present in these descriptions but the explanatory power afforded to them is at best reduced to a 'trigger' for mental states and 'self-control problems', 'habits and status quo bias' and issues of 'trust' are key to understanding the observed effects. The physics associated with the material context is almost entirely absent, making it impossible to know how important (in energy terms) any of these effects are. 


\section{Energy Research and Social Science}

Similarly, but outside the normal energy research community, work on thermal perception by psychologists focuses on internal mental mechanisms by which people report feeling warmer in social contexts but such studies do nothing to estimate the physical equivalence of that effect in Watt hours or therms $[18,19]$. The lack of measurement of physical units as basic as kilowatt hours (KWh) is important for policy: if the key aim is to reduce the total amount of electricity needed to maintain or develop some social context, how can one judge whether option A is a better approach than option B? It may be that social contexts help drive down energy demand by $10 \%$ suggesting policies that support greater social gathering, compared say with insulation. But at the moment, without such data it is impossible to tell.

\section{Sociological and social theory approaches to energy research}

The dominant theoretical framework for understanding energy via a sociological or social theory lens is the use of 'social practice theory' derived via the work of Gidden's [20] and Bourdieu [21] and other social theorists, and developed in the energy field by Reckwitz [22], Shove [23] and Hargreaves [24] among others. This approach is distinct from the psychological and behavioural approaches insofar as it foregrounds the role of social practices. Social practices can be understood as networks of actions (or the competency to carry out the right actions), things or materials that support the performance of practices, and meanings that correspond to recognisable and persistent parts of routines that make up important aspects of social life and give reason to the performance of a practice. This tripartite formulation of practices is most clearly promoted by the work of Shove and Pantzar [25] and emphasises the importance of materials. This foregrounding and focusing on the material context of practices is an important development for energy where materials and technologies are both obvious and important ${ }^{3}$. A classic example of the degree to which practice-based research focuses more on the symbolic rather than the physical treatment of the material is Hargreaves study of in home displays [27]. This excellent study documents via mainly qualitative methods how those living with in home displays react to them. However, the study makes only six mentions of any units of actual energy units of measurement (e.g. kilowatt hours) and then only in the context of either describing the functioning of the displays or in discussing the meaning of this unit with those using them. While absolutely invaluable as a set of findings to understand how in home displays are received, it does nothing to highlight how important the findings are for addressing strategic policy aims as highlighted above.

\section{What are we doing in the social sciences of energy research? A brief content analysis}

The non-systematic, narrative illustration of how two polar-opposite social science approaches to energy research above serves provides some weight to the argument presented here. Nevertheless, it has a distinct weakness: perhaps unconscious biases led to

\footnotetext{
${ }^{3}$ The close reader of this approach will notice that mental states are actually also implicitly important to social practice theory, but interestingly the focus is more on motor (actions) and, arguably, affective (meanings) aspects of psychological processes than the 'cognitive' processes per se, though cognition is clearly important too (symbol interpretation, learning and memory are all important for meanings) and either way, the distinction between these domains within mainstream psychology is highly contested [26].
} 


\section{Energy Research and Social Science}

cherry-picking supporting examples? A stronger test would be to analyse a corpus of research that is unarguably representative of social studies of energy and aim to understand whether physics is relatively absent and if so whether that absence is implicated in the absence of policy impact. The recent rise of the Energy Research and Social Science (ER\&SS) journal makes just such an analysis straightforward. It is without question the journal for broader social science-led studies of energy. This is not to say that such studies are not published elsewhere (for instance, the Hargreaves paper cited above is from Energy Policy) but prior analysis has shown the lack of broader social science input in major energy journals [5] and hence the reason for ER\&SS to be born. ER\&SS is therefore clearly a good proxy for the broader social science output in energy research. As such, the underpinning hypothesis - that social sciences do not commonly treat the material context with physical measurement - should be validly testable by analysis of the content of this corpus of research. Essentially, if the results show that a significant proportion of social science research does include a meaningful treatment of the material context, then this hypothesis, and the policy impact hypothesis it supports, will be shown to be wrong.

This of course begs the question of what constitutes 'a significant proportion' and 'meaningful treatment'? How can that even be reasonably determined in research outputs?

\section{Defining 'a significant proportion'}

One way to determine a plausible threshold proportion of ER\&SS papers that equates to 'significant' (i.e. likely sufficient for policy impact) is to calibrate the level of output against another academic journal that is aimed squarely at policy impact. The most obvious candidate here is Energy Policy that regards "international agencies, governments, public and private sector entities, local communities and non-governmental organisations" as a key audience. The point then is to say that the proportion of papers in Energy Policy that make any mention of the common physical metrics can set the bar for what 'significant proportion' comprises in this context. This can then be compared with the proportion within ER\&SS and thus test this aspect of the hypothesis. A comparison with another academic journal that is otherwise closely matched to ER\&SS suggests this is a reasonable approach at this point.

\section{Defining 'Meaningful treatment'}

The next important question is how to determine whether the papers in ER\&SS are providing a 'meaningful treatment' of physics. This issue divides into two parts: first, how to determine whether a paper has treated the physical aspect at all, and second how to determine whether the level of treatment within a paper is 'meaningful'. One obvious way to address the first part is to identify the presence of variations on common physical metrics in energy research. These include metrics such as variations on Watt hours (Wh) of course, but might also include climate policy oriented units such as variations of tonnes of oil equivalent (toe). Other obvious measures include temperature units relevant to energy in buildings contexts such as Celsius $\left({ }^{\circ} \mathrm{C}\right)$ and Fahrenheit $\left({ }^{\circ} \mathrm{F}\right)$. Also important here are the common measure of thermal resistance: $u$-values. The presence of these units specifically in their abbreviated form used as means of representing physical metrics (as opposed to their 'symbolic' treatment, such as with Hargreaves et al [27] above) can then be used as the 


\section{Energy Research and Social Science}

basis for determining the presence of meaningful treatment of physics. Importantly, the presence of these metrics is of course merely a proxy for the meaningful treatment of physics in a body of literature. Since there are many other metrics and other ways in which physics can be incorporated, the logic runs that any individual body of literature that treats physics meaningfully will have a significant representation of papers using physical units. Further, that within that group, the units identified above will be among the most common, and therefore the best proxy. Thus the goal here is not to establish the absolute volume of treatment in a policy-relevant literature, but the proportion, in order to understand how far from that overall volume social science-led literature on energy is. The proportion, the argument runs, is indicative of the degree to which physics is important in making policyrelevant research in this area.

This gives rise to the next issue which is how to determine whether a paper is making 'meaningful' use of these metrics. Clearly a single mention is likely not 'meaningful' - but how can we determine what is a fair measure in this context? Again, we can benchmark against Energy Policy articles. Given the mix of studies that Energy Policy publishes, there is likely a distribution of papers with different levels of mentions that go from almost pure social science approaches (such as Hargreaves et al as mentioned above) to much more technical and economic papers. With no a priori assumption about the spread of articles, the most defensible starting point is to take the median figure for the distribution of mentions. This is calculated by taking all those Energy Policy articles that make any mention, ordering them by the number of mentions and to take the value in the middle of that range as the cut off between a notional 'few mentions' and 'many mentions' with the latter providing the 'meaningful treatment' threshold. While this approach has clear shortcomings, the additional resources required to undertake a more detailed and nuanced analysis is unlikely to provide significantly more validity. That said it may well be useful for future research to understand more broadly what is the nature of the any gap identified here.

\section{Methods}

All original Energy Research and Social Science articles from all completed volumes (1-17) at the time of writing (July 2016) were downloaded and imported into NVivo 11. Articles that were not included in this were Short Communications, Book Reviews, Introductions to special editions and messages from the editorial board. This resulted in 290 articles as the source data for the main analysis. Text searches were then conducted across this corpus to find instances of physical measures being used. Eight terms were initially chosen on the basis of their common usage in much physical science-based research in energy and on the basis of them being unique strings of letters with standardised spelling - increasing search validity and precision. These comprised four variations on Watt-hour: $\mathbf{M W h}, \mathbf{k W h}, \mathbf{G W h}$, TWh (mega-, kilo-, giga- and tera-); temperature units ${ }^{\circ} \mathrm{C}$ and ${ }^{\circ} \mathrm{F}$; u-value; and Mtoe and ktoe (mega- and kilotonne of oil equivalent). However, initial test searches revealed that NVivo $11^{\prime}$ 's text search facility failed to identify the 'degree' symbol $\left({ }^{\circ}\right)$ in relation to ${ }^{\circ} \mathrm{C}$ and ${ }^{\circ} \mathrm{F}$, returning false positives for any $\mathrm{C}$ or $\mathrm{F}$ in the papers. Consequently, the temperature measures were excluded from the final search. 


\section{Energy Research and Social Science}

The articles were then classified into three groups: no mentions, few mentions (those where the number of mentions fell below the cut-off point established by analysis of the Energy Policy papers) and many mentions (those that were equal or above the cut-off)..

For the benchmarking the same searches were conducted on 229 papers drawn from three randomly selected volumes of the journal Energy Policy. The three volumes chosen were volume 60 (September 2013), volume 67 (April 2014) and 85 (October 2015) covering the same time period as the Energy Research and Social Science papers. The number of volumes sampled was kept to three in order to provide a similar number of papers as that included in ER\&SS analysis. As above, editorials and other non-original research article articles were excluded. A conscious effort was made to avoid special issues in order to avoid accidentally selecting a topic which would skew the selection of articles in favour of those demanding physical science measures in particular. Differences in the observed frequencies in occurrences of the terms above will indicate the scale of the social sciences' 'blind spot' for physical science in policy-relevant energy research.

\section{Results}

The initial analysis of Energy Policy data revealed a median of 10 mentions of these units within those that had any mentions of the units used. This therefore determined the difference between few mentions and many mentions for ER\&SS articles, the latter providing an operational definition of 'meaningful treatment' of the physical aspects of the context.

Table 1 summarises the findings of the content analysis for studies in Energy Research and Social Science. Overall, the vast majority (72\%) of articles made no mention of these physical unit names at all. Of the remaining $28 \%$ over three quarters made fewer than 10 mentions of these units ( $21 \%$ overall). The remaining third -19 articles in total or $7 \%$ of the number of papers - made more 10 or more mentions.

\begin{tabular}{lrr}
\hline Classification & No. of articles & \% of total \\
Many mentions $(>=10)$ & 19 & 7 \\
Few mentions $(<10)$ & 62 & 21 \\
No mentions & 209 & 72 \\
\hline Total & $\mathbf{2 9 0}$ & $\mathbf{1 0 0}$ \\
\hline
\end{tabular}

Table 1: Number and percentage of articles mentioning the key terms in Energy Research and Social Science

The distribution within the 'many mentions' group is also strongly skewed towards fewer mentions: the mean mentions in this group is 20.8 , yet $73 \%$ of the papers make 21 or fewer mentions. Of the 5 articles that make more than 20 mentions, only 2 mention more than one unit. As a validation of this method, a brief assessment of these top 5 mentioning articles [28-32] indicated that at least 4 of them represent the sort of research that is suggested here is needed (this is explored further below). Only Fattori et al. [31] potentially falls outside of this group due to its focus on modelling: since modelling rests on available data and since available data is almost entirely from the standard techno-economic 
approach, it seems reasonable to argue that first we need more studies with new kinds of data before generating new models which help explain any observed patterns.

The pattern for Energy Policy is shown in Table 2. More papers mention these terms (53\%) at least once than don't (47\%). Of those that mentions the terms, the split is one third 'many' (33\%), two thirds 'few' (67\%).

\begin{tabular}{lrr} 
Classification & No. of articles & \% of total \\
Many mentions $(>=10)$ & 41 & 18 \\
Few mentions $(<10)$ & 85 & 37 \\
No mentions & 103 & 47 \\
\hline Total & $\mathbf{2 2 9}$ & $\mathbf{1 0 0}$ \\
\hline
\end{tabular}

Table 2: Number and percentage of articles mentioning the key terms in Energy Policy

The pattern for Energy Policy is quite different from that observed for ER\&SS. Papers in Energy Policy are nearly twice as likely to make use of physical science units than are papers in ER\&SS: there is a 30 percentage point difference between the 'no mention' groups. For those papers that do make mention, there are over twice as many that make 'Many' mentions. Interestingly, out of all the papers analysed across the two journals, the two papers that came out with the most mentions overall were both from ER\&SS by some distance (66 and 64 mentions compared to 49 mentions for the top-placed Energy Policy article).

The key comparison here is the relative proportion of mention frequencies between journals than rather than the absolute levels within. This is since the argument is not that ER\&SS should be more like Energy Policy, but that if ER\&SS is to be taken as a representative platform for social science-oriented research on energy, then the proportion of articles passing the 'many mentions' mark should be closer to the level observed in Energy Policy if greater impact on policy is to be achieved. The pattern observed indicates that for ER\&SS research to reach the same distribution of no, few and many mentions, there would need to be over 50\% more studies making any reference to physical units and a more than doubling (from a low base) of the volume of research that presents a meaningful treatment of physics.

\section{Discussion}

This brief but systematic analysis of social science energy research supports the claim that too few social science studies integrate physical science to warrant the deep influence on energy policy many claim it should. The analysis above, it should be emphasised, is not targeted at ER\&SS, but rather the wider social science energy research community. The findings from the analysis suggest there needs to be a significant increase in interdisciplinary research that combines social and technical perspectives on energy, if the value of social science perspectives is to be brought deeper into policy. Of course this highlights a conundrum implicit in the introduction, and identified in the literature: how can social science work with physical science as an equal partner, rather than being an 'end of pipe' 


\section{Energy Research and Social Science}

service that addresses only issues of persuasion, acceptance and attitudes [7]? The point here is not to strengthen the standard model of energy policy making, but to transform it. The point here is that this is not about improving the standing of social science per se, but in making better energy policy through the incorporation of important social science concepts at the heart of energy research. The point of increasing the volume of research in this space is about generating a critical mass of data and knowledge that can become the de facto standard for energy modelling, and for reasoning about what approaches might work best to address challenges revealed in a new way by such an analysis. To generate more of this new kind of integrated, balanced interdisciplinary research, new research approaches are likely required. This is explored further below.

\section{Towards a socio-technical research paradigm?}

The fact that there are two communities of energy researchers - those that conduct mainly technical studies and those that conduct mainly social studies - leaves us with a status quo of technical research dominating evidence for energy policy and the contribution of social sciences either bolted on or overlooked, for reasons set out above. Despite the need to generate evidence that reflects the integrated socio-technical nature of energy for energy policy, there are few studies that can be meaningfully described as 'socio-technical' in this integrated sense. As I have explored elsewhere, there are many studies that make use of social science methods either alongside or as part of technical studies of energy [33] - what Love and Cooper call 'social and technical' as opposed to 'socio-technical' research argued for here.

'Social and technical' studies commonly fail to integrate social and physical science approaches sufficiently or validly either to prevent the latter dominating the former, or the former making sense of the latter. If energy policy is to work for people and society, research that informs it must start with understanding what role energy plays in society and the lives of people. Consequently, social science-led journals like Energy Research and Social Science are well-placed to promote the development of a more balanced, socio-technicallyoriented research paradigm perhaps in partnership with other more technically-oriented journals.

This begs the question 'what is socio-technical research?' Following Love and Cooper, this is intended to describe an approach to research that seeks to integrate physical science methods and measures of technical and/or environmental aspects of a context with social science methods and measures. The term relates directly to a mode of interdisciplinary research where the foundational assumptions and theories informing the approach incorporate both physical and social concepts - or indeed, socio-physical, socioenvironmental or socio-technical concepts such as 'home' as opposed to house, dwelling or household [34]. This distinguishes the use of the term to describe, for instance, standard social science studies of socio-technical systems [e.g. 35] or social sciences studies that take place in a context where technical units of measurement have previously been taken for other purposes [e.g. 36]. The distinctive feature of socio-technical research is that it is likely to challenge accepted physical units of analysis and create new kinds of variables reflecting the socio-technical nature of energy. For instance, in understanding domestic heating patterns, physical data aims to estimate the 'mean internal temperature' often with specific 


\section{Energy Research and Social Science}

spatial or temporal resolution. Social data is often spatio-temporally generic, even within the same study (e.g. survey interviews asking 'how comfortable are you typically'). Integrated approaches would seek (for instance) to align data collection across these channels (e.g. by getting more spatio-temporally defined subjective ratings). This enables not only understanding how (or whether) reports of comfort are associated with specific temperature recordings in specific places but also the potential to reveal the spatiotemporal dynamics of comfort (how warm or cold temperatures prior to reporting affect subjective responses) among many other possible avenues of exploration. In this example, research might focus on generating a 'person-centred mean internal temperature' measure, where internal temperatures where someone is present generates are combined to form a new unit of analysis for understanding energy efficiency for internal thermal comfort. More broadly, socio-technical research approaches could affect sampling strategies for large scale quantitative surveys (e.g. sampling around energy network components), as well as the development and deployment of monitoring equipment [37].

The analysis of ER\&SS above already identified studies that are showing signs of these characteristics, and will help to determine and define what a socio-technical research paradigm of the sort outlined above might look like. Of the top five studies making the most mention of the physical science units in ER\&SS, we find three empirical studies generating new raw data, and two analytic papers that either take a modelling [31] or science and technology studies [28] perspective. While these might count as socio-technical a broader sense, my position here is that these are social studies of energy systems that make a valuable contribution to the policy and academic debates in part by virtue of their relatively strong use of standard physical science variables. The other three studies present a better model of an emergent socio-technical research paradigm, indicated in part by their use of variations of physical science units that serve to foreground (or at least may prevent backgrounding) the spatio-temporal dynamics of social life [e.g. 38-40].

Burgett's [32] analysis of the whole house switch utilises the large scale (somewhat) social and (mostly) technical Residential Energy Consumption Survey - and seeks to examine the role of a new technology introduced to affect routines of electricity use. He uses common units of energy analysis (kWh/year) as well as less-often deployed, but potentially more socio-technical energy intensity units such as $\mathrm{kWh} / \mathrm{sqft}$ (square foot) - at least insofar as space is acknowledged, albeit treated uniformly without regard to the social uses of the spaces measured. The important aspect of Burgett's analysis is the way he tries to bring together the material aspects that constitute a range of practices in American homes together with the physical characteristics based on a range of real world data. This enables what amounts to a secondary socio-technical analysis that pushes forwards the boundary of socio-technical research.

Chidebell-Emordi's [30] analysis of fuel poverty in Nigeria develops an approach that enables a context-specific measure of energy poverty based on the material configuration that supports common practices. This supported an analysis of the per capita energy consumption which is clearly move in the right direction in terms of generating units of analysis that bring social and human aspects of energy use to the fore. 


\section{Energy Research and Social Science}

Finally, Liddell's [29] analysis of human factors in Northern Irish homes also looks to map out the way in which a new configuration of materials (Passivhaus-type new homes) impacts on comfort-oriented practices in low income households. Her study characterises some of the materials by making use of a range of straightforward physical units ( $\mathrm{kWh}$, u-values and ${ }^{\circ} \mathrm{C}$ ) but also those that might be described as (potentially) more socio-technical such as heating degree days (HDD). Such a widely used measure can be seen as offering the potential for a more socio-technical analysis insofar as it could capture routines of heating, even if (as noted below) in practice the calculation of HDD directly glosses over social dynamics. Liddell's use of a longitudinal design is also likely critical in enabling social factors to be revealed at different temporal scales.

While each of these studies arguably represent among the most 'socio-technical' of studies within ER\&SS, there are still important limitations that prevent them from being full archetypes of socio-technical research as set out by Love and Cooper [33]. Each of the studies was based on 'off the shelf' theories (implicitly or explicitly) of energy consumption, which themselves are each physical science-led theories. For Burgett, he used data from the RECS survey which is principally a technical survey executed via social survey methods. The kinds of data that are acquired through that approach is therefore technical data which limits the degree to which social factors can be surfaced. For Chidebell-Emordi, he deployed a standard understanding of fuel poverty, albeit defined in terms of Western European standards (based on the notion of fixed, minimum energy requirements derived from the idea of 'basic human needs'), and recalibrated it for the Nigerian context. A more radical, socio-technical approach would have aimed to redefine what kinds of energy-related poverties could exist within Nigeria, and with it an understanding of the material and social drivers and consequences. Similarly, Liddell's important study has at its foundation the notion of heating degree days based on standardised, fixed, context independent notions of internal temperature differentials set by the World Health Organisation. Also Liddell did not appear to analyse (or at least report on) energy at a temporal frequency more fitting to capture the rhythms of daily life, limiting the analysis to fortnightly consumption. This meant that when important early glitches in the ventilation system resulted in excess demands for payments from the residents, she did not assess the energy consequences of that which could have had important implications for policy.

\section{Conclusions}

The analysis above sets out a new diagnosis for why the broader social sciences fail to have an adequate impact on energy policy-making. Fundamentally, there are too few studies that take into account the physics of the energy system in the heart of their design. This leaves the fundamental units for understanding energy to technical researchers who ultimately dominate the discourse of energy policy. While researchers are making progress towards the inclusion of more physical science units within social studies of energy, much more needs to be done to ensure the social character of the physical is foregrounded. The analysis here indicates that not only do social scientists need to engage with physical scientists as others have urged [1, 7], significantly (two times?) more studies need to be produced that can redefine the physical units of energy in a way that brings social concerns to the fore. In so doing, the argument here runs, the broader social sciences will be able make a much stronger impact on energy policy making, and with it the betterment of society. Whether 
Energy Research and Social Science

this holds in practice of course, remains to be seen: as ever, further research is necessary to explore how relevant this claim here is, in relation to other proposed barriers to impact. 


\section{Energy Research and Social Science}

\section{References}

1. Sovacool, B. K., Ryan, S. E., Stern, P. C., Janda, K., Rochlin, G., Spreng, D., ... Lutzenhiser, L. (2015). Integrating social science in energy research. Energy Research \& Social Science, 6, 95-99. doi:10.1016/j.erss.2014.12.005

2. Stern, P. C. (1985). Blind spots in policy analysis: What economics doesn't say about energy use. Journal of Policy Analysis \& Management, 5(2), 200-227.

3. Lutzenhiser, L. (1993). Social and Behavioral Aspects of Energy use. Annual Review of Energy and the Environment, 18(1), 247-289.

doi:10.1146/annurev.eg.18.110193.001335

4. Shove, E. (1998). Gaps, barriers and conceptual chasms: theories of technology transfer and energy in buildings. Energy Policy, 26(15), 1105-1112. doi:10.1016/S03014215(98)00065-2

5. Sovacool, B. K. (2014). What are we doing here? Analyzing fifteen years of energy scholarship and proposing a social science research agenda. Energy Research \& Social Science, 1, 1-29. doi:10.1016/j.erss.2014.02.003

6. Maxwell, K. B. (2014). Getting there from here. Nature Climate Change, 4(11), 936-937. doi:10.1038/nclimate2413

7. Sunstein, C. R., \& Thaler, R. H. (2009). Nudge: Improving Decisions About Health, Wealth and Happiness. London: Penguin.

8. Dolan, P., Hallsworth, M., Halpern, D., King, D., \& Vlaev, I. (2010). MINDSPACE. Retrieved from http://www.instituteforgovernment.org.uk/publications/mindspace

9. DECC. (2014). Advice on how to use heating controls: Evaluation of a trial in Newcastle. London UK: Department of Energy and Climate Change. Retrieved from 


\section{Energy Research and Social Science}

https://www.gov.uk/government/publications/advice-on-how-to-use-heatingcontrols-evaluation-of-a-trial-in-newcastle

10. DECC. (2014). Evaluation of the DECC/John Lewis energy labelling trial. London.

Retrieved from https://www.gov.uk/government/publications/evaluation-of-the-deccand-john-lewis-energy-labelling-trial

11. DECC. (2013). Removing the hassle factor associated with loft insulation: Results of a behavioural trial. London, UK. Retrieved from https://www.gov.uk/government/uploads/system/uploads/attachment_data/file/236 858/DECC_loft_clearance_trial_report_final.pdf

12. Collier, A. (1994). Critical Realism: An Introduction to Roy Bhaskar's Philosophy. London ; New York: Verso.

13. Li, N., Brossard, D., Anderson, A. A., Scheufele, D. A., \& Rose, K. M. (2016). How do policymakers and think tank stakeholders prioritize the risks of the nuclear fuel cycle? A semantic network analysis. Journal of Risk Research, 1-23. doi:10.1080/13669877.2016.1223164

14. Devine-Wright, P. (2005). Beyond NIMBYism: towards an integrated framework for understanding public perceptions of wind energy. Wind Energy, 8(2), 125-139. doi:10.1002/we.124

15. Butler, C., Demski, C., Parkhill, K., Pidgeon, N., \& Spence, A. (2015). Public values for energy futures: Framing, indeterminacy and policy making. Energy Policy, 87, 665-672. doi:10.1016/j.enpol.2015.01.035

16. Lowe, P., Phillipson, J., \& Wilkinson, K. (2013). Why social scientists should engage with natural scientists. Contemporary Social Science, 8(3), 207-222.

doi:10.1080/21582041.2013.769617 


\section{Energy Research and Social Science}

17. Never, B. (2016). Behave and save?: Behaviour, energy efficiency and performance of micro and small enterprises in Uganda. Energy Research \& Social Science, 15, 34-44. doi:10.1016/j.erss.2016.03.001

18. Williams, L. E., \& Bargh, J. A. (2008). Experiencing Physical Warmth Promotes Interpersonal Warmth. Science, 322(5901), 606-607. doi:10.1126/science.1162548

19. Zhong, C.-B., \& Leonardelli, G. J. (2008). Cold and Lonely Does Social Exclusion Literally Feel Cold? Psychological Science, 19(9), 838-842. doi:10.1111/j.1467$9280.2008 .02165 . x$

20. Giddens, A. (1984). The Constitution of Society: Outline of the Theory of Structuration. University of California Press.

21. Bourdieu, P. (1977). Outline of a Theory of Practice. (J. Goody, Ed.) (Vol. 16). Cambridge University Press. Retrieved from http://www.loc.gov/catdir/description/cam022/76011073.html

22. Reckwitz, A. (2002). Toward a Theory of Social Practices A Development in Culturalist Theorizing. European Journal of Social Theory, 5(2), 243-263. doi:10.1177/13684310222225432

23. Shove, E. (2010). Beyond the ABC: climate change policy and theories of social change. Environment and Planning A, 42(6), 1273 - 1285. doi:10.1068/a42282

24. Hargreaves, T. (2011). Practice-ing behaviour change: Applying social practice theory to pro-environmental behaviour change. Journal of Consumer Culture, 11(1), 79-99. doi:10.1177/1469540510390500

25. Shove, E., \& Pantzar, M. (2005). Consumers, Producers and Practices Understanding the invention and reinvention of Nordic walking. Journal of Consumer Culture, 5(1), 43-64. doi:10.1177/1469540505049846 


\section{Energy Research and Social Science}

26. Pessoa, L. (2013). The Cognitive-Emotional Brain: From Interactions to Integration. Cambridge, Massachusetts: MIT Press.

27. Hargreaves, T., Nye, M., \& Burgess, J. (2010). Making energy visible: A qualitative field study of how householders interact with feedback from smart energy monitors. Energy Policy, 38(10), 6111-6119. doi:10.1016/j.enpol.2010.05.068

28. Cointe, B. (2015). From a promise to a problem: The political economy of solar photovoltaics in France. Energy Research \& Social Science, 8, 151-161. doi:10.1016/j.erss.2015.05.009

29. Liddell, C. (2015). Human factors in energy efficient housing: Insights from a Northern Ireland pocket neighbourhood. Energy Research \& Social Science, 10, 19-25. doi:10.1016/j.erss.2015.06.004

30. Chidebell-Emordi, C. (2015). The African electricity deficit: Computing the minimum energy poverty line using field research in urban Nigeria. Energy Research \& Social Science, 5, 9-19. doi:10.1016/j.erss.2014.12.011

31. Fattori, F., Albini, D., \& Anglani, N. (2016). Proposing an open-source model for unconventional participation to energy planning. Energy Research \& Social Science, 15, 12-33. doi:10.1016/j.erss.2016.02.005

32. Burgett, J. M. (2015). Fixing the American energy leak: The effectiveness of a wholehouse switch for reducing standby power loss in U.S. residences. Energy Research \& Social Science, 6, 87-94. doi:10.1016/j.erss.2014.12.006

33. Love, J., \& Cooper, A. C. G. (2015). From social and technical to socio-technical: Designing integrated research on domestic energy use. Indoor and Built Environment, 24(7), 986-998. doi:10.1177/1420326X15601722 


\section{Energy Research and Social Science}

34. Cooper, A. C. (2016). Exploring the scope of science advice: social sciences in the UK government. Palgrave Communications, 2(16044), 1-9. doi:10.1057/palcomms.2016.44

35. Guy, S., \& Shove, E. (2000). The Sociology of Energy, Buildings and the Environment: Constructing Knowledge, Designing Practice. Psychology Press.

36. Verbong, G., \& Geels, F. (2007). The ongoing energy transition: Lessons from a sociotechnical, multi-level analysis of the Dutch electricity system (1960-2004). Energy Policy, 35(2), 1025-1037. doi:10.1016/j.enpol.2006.02.010

37. Ellsworth-Krebs, K., Reid, L., \& Hunter, C. J. (2015). Home -ing in on domestic energy research: 'House,' 'home,' and the importance of ontology. Energy Research \& Social Science, 6, 100-108. doi:10.1016/j.erss.2014.12.003

38. Hermwille, L. (2016). The role of narratives in socio-technical transitions-Fukushima and the energy regimes of Japan, Germany, and the United Kingdom. Energy Research \& Social Science, 11, 237-246. doi:10.1016/j.erss.2015.11.001

39. Chiu, L. F., Lowe, R., Raslan, R., Altamirano-Medina, H., \& Wingfield, J. (2014). A sociotechnical approach to post-occupancy evaluation: interactive adaptability in domestic retrofit. Building Research \& Information, 42(5), 574-590.

doi:10.1080/09613218.2014.912539

40. Cooper, A. C. G., Shipworth, D., \& Humphrey, A. (2014). UK Energy Lab: A feasibility study for a longitudinal, nationally representative socio-technical survey of energy-use (Synthesis Report). Retrieved from http://www.ucl.ac.uk/steapp/docs/lukesreports/synthesis 
Energy Research and Social Science

41. Southerton, D. (2013). Habits, routines and temporalities of consumption: From individual behaviours to the reproduction of everyday practices. Time \& Society, 22(3), 335-355. doi:10.1177/0961463X12464228

42. Hand, M., Shove, E., \& Southerton, D. (2007). Home Extensions in the United Kingdom: Space, Time, and Practice. Environment and Planning D: Society and Space, 25(4), 668681. doi:10.1068/d413t

43. Southerton, D., \& Tomlinson, M. (2005). 'Pressed for time'- the differential impacts of a 'time squeeze'. The Sociological Review, 53(2), 215-239. doi:10.1111/j.1467954X.2005.00511.x 